\title{
Analisis Risiko Investasi Infrastruktur Berbasis Fuzzy Analytical Hierarchy Process (F-AHP)
}

\section{Fuzzy Analytical Hierarchy Process (F-AHP) For Risk Assesment In Infrastructure Investment}

\author{
Lisherly Reginancy Debataraja ${ }^{1, a)}$, Akhmad Suraji ${ }^{1, b)}$ \& Taufika Ophiyandri ${ }^{1, c)}$ \\ 1) Jurusan Teknik SIpil, Fakultas Teknik, Universitas Andalas \\ Koresponden : ${ }^{a}$ liredraja@gmail.com, ${ }^{b}$ akmad.suraji@ft.unand.ac.id \& ${ }^{c}$ ophiyandri@ft.unand
}

\begin{abstract}
ABSTRAK
Pemenuhan infrastruktur sebagai aset memerlukan pengelolaan aset infrastruktur yang bertujuan untuk mendapatkan nilai atau "value" yang lebih besar untuk menghindari kerugian akibat risiko yang mungkin terjadi. Hal ini mendorong perlunya menganalisis skala risiko dari masing-masing elemen risiko yang berpengaruh terhadap kerugian proyek di Jalan Tol Padang-Sicincin dengan mengkombinasikan metode skala risiko dan severity index serta menganalisis bobot prioritas risiko antara dua elemen risiko dengan menggunakan proses F-AHP. Metode pengumpulan data menggunakan metode kuesioner yang dibagi dalam dua tahap dimana tahap pertama untuk menganalisis skala risiko dan tahap kedua untuk menganalisa bobot prioritas risiko. Bobot risiko yang dianalisis oleh proses F-AHP akan dibandingkan dengan hasil faktor andil pada Pedoman Analisis Risiko Investasi Jalan Tol Pd T-01-2005-B sebagai penentuan penerimaan atau pengalokasian risiko. Hasil dari penelitian ini didapatkan bahwa nilai bobot prioritas untuk tahap pra-konstruksi dan tahap konstruksi adalah 56,41\% dan 43,59\%. Risiko tahap pra konstruksi dan risiko tahap konstruksi dikategorikan sebagai risiko tinggi dengan nilai skala risiko masing-masing adalah 16 dan 12. Risiko yang memiliki kategori risiko sangat tinggi yaitu risiko ketersediaan lahan (PKLA01) dan risiko penolakan masyarakat (PKLA03). Risiko dengan nilai bobot prioritas tertinggi adalah risiko pembebasan lahan (PKLA) untuk tahap pra-konstruksi dan risiko Force Majeure (KFOR) selama tahap konstruksi.
\end{abstract}

Kata Kunci : manajemen infrastruktur, analisis risiko investasi, proses $F$ - $A H P$, bobot prioritas risiko.

\section{PENDAHULUAN}

Ketersediaan infrastruktur merupakan sebuah hal yang mendasar untuk mendukung aktivitas perekonomian suatu bangsa. Peran insfrastruktur dalam arti fisik seperti jaringan jalan selayaknya dikelola sebagai aset fisik yang diharapkan mampu memenuhi kebutuhan masyarakat saat ini dan dimasa yang akan datang. Dalam pemenuhan itu pemerintah masih berupaya meningkatkan penyediaan infrastruktur jalan tol di Indonesia dan bekerjasama dengan pihak swasta (investor, kontraktor, dan operator) untuk mewujudkan penyediaan infrasruktur jalan tol tersebut. Pemenuhan infrastruktur sebagai aset memerlukan pengelolaan aset infrastruktur yang bertujuan untuk mendapatkan nilai atau "value" yang lebih besar dan mencapai tujuan utama bagi pemiliknya. Pengelolaan/manajemen aset pada infrastruktur dengan menggunakan pendekatan sistematis berupa pengetahuan/science dan program disebut sebagai manajemen aset infrastruktur (Suprayitno \& Soemitro, 2018). Manajemen aset 
infrastruktur ini memerlukan tools untuk menganalisa aset tersebut seperti operasi penelitian, statistika, pengambilan keputusan (decision making), manajemen kualitas (quality management), manajemen strategis (strategic management), dan manajemen risiko (risk management) (Suprayitno \& Soemitro, 2018). Pengelolaan aset pada infrastruktur tidak hanya disaat masa pemeliharaan atau pada masa pasca konstruksi namun juga pada masa pra konstruksi dan pada masa konstruksi itu sendiri.

Hal ini mengindikasikan bahwa risiko proyek pada infrastruktur perlu dihitung dan diperhatikan secara serius. Untuk mengatasi risiko tersebut maka perlu disadari dan diketahui bahwa pentingnya menghitung nilai faktor risiko sebagai salah satu tahap manajemen risiko demi tercapainya sasaran proyek secara sistematis, terkendali dan terukur (Fang, 2011).

Pada saat ini direncanakan Jalan Tol Padang - Sicincin sepanjang $28 \mathrm{~km}$ yang merupakan bagian dari tahapan jalan tol Padang - Pekanbaru. Dalam penelitian ini akan dianalisis risiko investasi tahap pra konsruksi dan tahap konstruksi berdasarkan persamaan faktor risiko investasi, dimana besaran faktor risiko tersebut merupakan gambaran mengenai tingkat risiko investasi yang terjadi. Analisis faktor risiko dilihat dari besaran dampak (impact) dan kemungkinan (probability) kejadian risiko. Nilai dampak dan nilai kemungkinan merupakan input dari persepsi atau pendapat dari responden berkompeten dalam risiko di proyek konsruksi jalan tol Padang-Sicincin. Pendapat tersebut akan dianalisis dengan menggunakan Logika Fuzzy Analitycal Hierarchy Process (FAHP) sebagai metode untuk memberikan nilai subjektif tentang setiap variabel risiko dengan interval 0 hingga 1.

Faktor risiko yang dianalisis dengan metode Fuzzy Analitycal Hierarchy Process (FAHP) akan dibandingkan dengan hasil analisa risiko dengan parameter dampak dan probabilitas yang dikeluarkan oleh Puslitbang Pd T-01-2005-B Pedoman Analisa Risiko Investasi Jalan Tol. Selanjutnya penentuan respon/mitigasi risiko tersebut dilakukan berdasarkan peringkat risiko SNI.

\section{METODA PENELITIAN}

Penelitian ini merupakan penelitian yang menggunakan kombinasi dari teknik kualitatif dan teknik kuantitatif. Pengumpulan dan pengolahan data dibagi dalam dua tahap, tahap pertama membahas penilaian bobot risiko dengan menggunakan metode Fuzzy Analytical Hierarchy Process (F-AHP) dan tahap kedua menganalisis skala risiko terkait tingkat kemungkinan dan dampak yang mungkin terjadi dengan menggunakan parameter skala likert dan metode severity index dimana untuk menganalisis masing masing kategori risiko menggunakan persamaan rata-rata geometric mean. Penelitian ini menggunakan dua sumber data yaitu data primer dan data sekunder, dimana data primer merupakan data yang diambil dari responden ahli dengan menggunakan teknik kuisioner, dan data sekunder merupakan daftar risiko yang diambil dari Puslitbang Pd T-01-2005-B.

\section{Analisis Kategori Risiko Proyek}

Risiko merupakan ketidakpastian yang dapat berdampak pada sasaran (Susilo \& Kaho, 2018). Investasi merupakan kegiatan penanaman modal yang diharapkan untuk memperoleh keuntungan. Risiko investasi dalam Pedoman Pd T-01-2005-B menyatakan bahwa risiko investasi adalah kerugian bagi para investor yang diakibatkan oleh kejadian atau peristiwa tak terduga yang dapat menimbulkan adanya penambahan biaya, keterlambatan, dan pendapatan yang tidak sesuai dengan rencana (Pd T-01-2005-B, 2005).

Untuk penilaian kategori risiko pada penelitian ini menggunakan matriks kemungkinan $(\mathrm{P}(\mathrm{e})$ ) dan dampak $(\mathrm{P}(\mathrm{i})$ ). Nilai dari $\mathrm{P}(\mathrm{e})$ dan $\mathrm{P}(\mathrm{i})$ didapat dari gabungan rata-rata geometrik responden dianalisis menggunakan skala likert dan metode severity index. Skala likert merupakan skala yang digunakan untuk mengukur level pendapat responden. Kesesuaian matriks dalam memperkirakan tingkat kemungkinan dan dampak sangat dibutuhkan untuk 
menentukan kategori dan prioritas risiko (Baccarini \& Archer, 2001). Matriks kemungkinan dampak yang digunakan dalam penelitian ditampilkan pada Tabel 1 yang telah ditentukan oleh peneliti, untuk kategori risiko dan prioritas risiko ditampilkan pada Tabel 2 dibawah ini.

Tabel 1. Matriks Kemungkinan Dampak

\begin{tabular}{|c|c|c|c|c|c|}
\hline 5 & 5 & 10 & 15 & 20 & 25 \\
\hline 4 & 4 & 8 & 12 & 16 & 20 \\
\hline 3 & 3 & 6 & 9 & 12 & 15 \\
\hline 2 & 2 & 4 & 6 & 8 & 10 \\
\hline \multirow[t]{2}{*}{1} & 1 & 2 & 3 & 4 & 5 \\
\hline & 1 & 2 & 3 & 4 & 5 \\
\hline
\end{tabular}

Kemungkinan terjadi

Tabel 2. Kategori dan Respon Risiko

\begin{tabular}{cccc}
\hline Skala & Kategori & Prioritas & Respon \\
\hline $1-3$ & Sangat Rendah & 5 & Diterima \\
$4-6$ & Rendah & 4 & Mitigasi \\
$8-10$ & Sedang & 3 & Transfer \\
$12-16$ & Tinggi & 2 & Alokasi \\
$20-25$ & Sangat Tinggi & 1 & Ditolak \\
\hline
\end{tabular}

Sebelum menentukan kategori risiko, nilai kemungkinan dan dampak dianalisis dengan metode severity index (SI). Mengacu kepada penelitian yang dilakukan oleh Marantika (2017) analisis dengan severity index (SI) dijabarkan berdasarkan formula berikut :

$$
S I=\frac{\sum_{i=0}^{4} a i x i}{4 \sum_{i=0}^{4} 0 x i} x(100 \%)
$$

Keterangan :

$$
\begin{aligned}
& \text { ai } \quad=\text { konstanta penilai } \\
& \mathrm{xi} \quad=\text { frekuensi responden } \\
& \text { I } \quad=0,1,2,3,4, \ldots \mathrm{n} \\
& \mathrm{x} 0, \mathrm{x} 1, \mathrm{x} 2, \mathrm{x} 3, \mathrm{x} 4=\text { nilai frekuensi responden } \\
& \mathrm{x} 0 \quad \text { frekuensi "sangat kecil/rendah" maka } \mathrm{a} 0=0 \\
& \mathrm{x} 1 \quad=\text { frekuensi "kecil/rendah" maka a1 }=1 \\
& \text { x2 }=\text { frekuensi "sedang" maka a1 }=2 \\
& \text { x3 }=\text { frekuensi "besar" maka a1 = } 3 \\
& \mathrm{x} 4=\text { frekuensi " sangat besar" maka } \mathrm{a} 1=4 \\
& \mathrm{a} 0=0, \mathrm{a} 1=1, \mathrm{a} 2=3, \mathrm{a} 4=4
\end{aligned}
$$

Nilai SI dimasukkan kedalam Tabel 3 untuk menentukan skala kemungkinan dan dampak. 
Tabel 3. Nilai Severity Index

\begin{tabular}{ccc}
\hline Kategori & SI & Sk ala \\
\hline Sangat Rendah & $0 \%<$ SI $<20 \%$ & 1 \\
Rendah & $20 \%<$ SI $<40 \%$ & 2 \\
Sedang & $40 \%<$ SI $<60 \%$ & 3 \\
Tinggi & $60 \%<$ SI $<80 \%$ & 4 \\
Sangat Tinggi & $80 \%<$ SI $<100 \%$ & 5 \\
\hline
\end{tabular}

\section{Fuzzy Analytical Hierarchy Process (FAHP)}

F-AHP merupakan suatu konsep gabungan Metode Fuzzy dan Analytical Hierarchy Process (AHP) (Saaty, 2004). FAHP merupakan perluasan dari AHP dengan pandangan manusia yang direkam dalam bilangan $f u z z y$, oleh karena itu bentuk perbandingan matriks juga diubah ke bilangan fuzzy. Akan tetapi, untuk mengubah bobot dari matriks perbandingan fuzzy terdapat perlakuan tambahan sebagai operasi matriks bilangan fuzzy yang membedakan dengan bilangan fuzzy (Özdağoğlu, 2007). Dalam hal ini, banyak variasi algoritma yang bertujuan untuk memproses matriks berpasangan fuzzy dan merubah ke bobot prioritas. Beberapa algoritma yang popular ditemukan oleh Van Laarhoven dan Pedrycz, Buckley, Boender, De Graan dan Lootsma, Deng (Ahmed \& Kilic, 2016). Diantara banyak algoritma FAHP, Fuzzy Extent Analysis (FEA) yang ditemukan oleh Chang adalah metode yang paling sering digunakan dalam algoritma FAHP (Chang, 1996). FEA menggunakan konsep dari perluasan analisis dengan mengkombinasikan derajat kemungkinan untuk menghitung bobot dari matriks berpasangan fuzzy. Proses menghitung bobot risiko dengan menggunakan metode FAHP dijelaskan pada langkah-langkah berikut :

\section{Dekomposisi}

Dekomposisi merupakan langkah awal untuk membagi elemen risiko berdasarkan level nya ke dalam bentuk hierarki agar lebih terstruktur dan sistematis.Struktur hierarki dimulai dari goal atau tujuan yang hendak dicapai selanjutnya diikuti berdasarkan level kriteria untuk elemen risiko dan level subkriteria untuk level subrisiko. Berikut bentuk hierarki yang digunakan dalam penelitian ini.

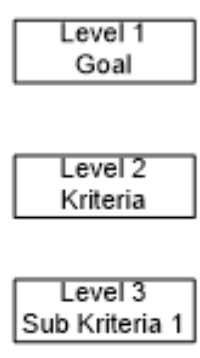

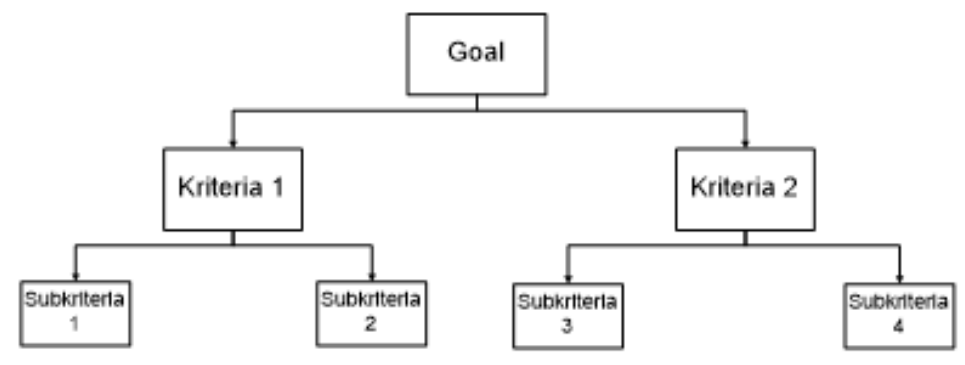

Gambar 1. Hierarki FAHP

\section{Fuzifikasi}

Fuzifikasi merupakan proses mengubah data masukan berupa pendapat responden yang nilai kebenarannya pasti (crisp input) ke dalam bentuk fuzzy input yang ditentukan berdasarkan fungsi keanggotaan. Langkah selanjutnya melakukan penalaran dan pengolahan menggunakan fuzzy input untuk menghasilkan fuzzy output yang diubah menjadi crisp rule berdasarkan fungsi keanggotaan yang telah ditentukan. Untuk menentukan derajat keanggotaan pada FAHP maka disusun Triangular Fuzzy Number (TFN) atau bilangan segitiga fuzzy. Inti dari metoda F-AHP yang berada pada perbandingan nilai berpasangan tersebut digambarkan dengan skala rasio 
yang berhubungan dengan nilai skala fuzzy. Ketentuan fungsi keanggotaan yang terdiri dari lima skala linguistik dapat dilihat pada Tabel 4 berikut (Triantaphyllou \& Mann, 1995) :

Tabel 4. Nilai Triangular Fuzzy Number untuk Skala Likert

\begin{tabular}{|c|c|c|c|c|}
\hline Defenisi variabel linguis tik & Skala Like rt & Nilai TFN & & Nilai TFN \\
\hline \multirow{2}{*}{$\begin{array}{c}\text { Dua kriteria saling memiliki risiko } \\
\text { yang sama }\end{array}$} & 1 & $(1,1,1)$ & $1 / 1$ & $(1 / 1,1 / 1,1 / 1)$ \\
\hline & 2 & $(1,2,4)$ & $1 / 2$ & $(1 / 4,1 / 2,1 / 1)$ \\
\hline \multirow{2}{*}{$\begin{array}{c}\text { Satu kriteria sedikit lebih berisiko } \\
\text { dari yang lainnya }\end{array}$} & 3 & $(1,3,5)$ & $1 / 3$ & $(1 / 5,1 / 3,1 / 1)$ \\
\hline & 4 & $(2,4,6)$ & $1 / 4$ & $(1 / 6,1 / 4,1 / 2)$ \\
\hline \multirow{3}{*}{$\begin{array}{c}\text { Satu kriteria lebih berisiko dari yang } \\
\text { lainnya }\end{array}$} & 5 & $(3,5,7$ & $1 / 5$ & $(1 / 7,1 / 5,1 / 3)$ \\
\hline & & & & \\
\hline & 6 & $(4,6,8$ & $1 / 6$ & $(1 / 8,1 / 6,1 / 4)$ \\
\hline \multirow{2}{*}{$\begin{array}{c}\text { Satu kriteria sangat lebih berisiko } \\
\text { dari yang lainnya }\end{array}$} & 7 & $(5,7,9)$ & $1 / 7$ & $(1 / 9,1 / 7,1 / 5)$ \\
\hline & 8 & $(6,8,10)$ & $1 / 8$ & $(1 / 10,1 / 8,1 / 6)$ \\
\hline $\begin{array}{l}\text { Satu kriteria mutlak sangat lebih } \\
\text { berisiko dari yang lainnya }\end{array}$ & 9 & $(7,9,11)$ & $1 / 9$ & $(1 / 11,1 / 9,1 / 7)$ \\
\hline
\end{tabular}

\section{Uji Konsistensi}

Uji konsistensi digunakan untuk meneliti seberapa besar nilai konsistensi matriks berpasangan. Untuk mengukur ketidakkonsistenan yang ada dalam matriks berpasangan dapat dianalisis berdasarkan persamaan dibawah ini (Saaty, 2004) :

$$
C I=\frac{\lambda_{m a k s}-\mathrm{n}}{n-1}
$$

Menurut Saaty (2004) suatu matriks perbandingan berpasangan dinyatakan konsisten apabila nilai rasio konsistensi CR $\leq 10 \%$.Persamaan CR tersebut dapat dilihat sebgai berikut :

$$
C R=\frac{C I}{R I}
$$

Nilai RI atau nilai random indeks merupakan nilai yang dikeluarkan oleh Oarkridge Laboratory. Nilai RI dapat dilihat seperti Tabel 5 dibawah ini (Abbasianjahromi, 2013) :

Tabel 5. Nilai Random Indeks ( RI)

\begin{tabular}{|c|c|c|c|c|c|c|c|c|}
\hline $\mathrm{N}$ & 1 & 2 & 3 & 4 & 5 & 6 & 7 & 8 \\
\hline $\mathrm{RI}$ & 0 & 0 & 0.58 & 0.9 & 1.12 & 1.24 & 1.32 & 1.41 \\
\hline $\mathrm{N}$ & 9 & 10 & 11 & 12 & 13 & 14 & 15 & \\
\hline $\mathrm{RI}$ & 1,45 & 1,49 & 1,51 & 1,48 & 1,56 & 1,57 & 1,59 & \\
\hline
\end{tabular}

\section{Fuzzy Synthetic Extent}

Analisis Fuzzy Synthetic Extent digunakan untuk memperoleh perluasan suatu objek sehingga didapatkan nilai extent analysis $M$ (Ahmed \& Kilic, 2016).

Jika $g=\left\{g_{1}, g_{2}, g_{n}\right)$ merupakan sekumpulan kriteria atau parameter sebanyak $\mathrm{n}$ dan $\mathrm{A}=$ $\left\{A_{1}, A_{2}, A_{m}\right)$ merupakan sekumpulan keputusan sebanyak $m$, maka didapatkan nilai extent 
analysis $M$ yaitu $M_{g_{i}}^{1}, M_{g_{i}}^{2}, M_{g_{i}}^{m}$, dimana $\mathrm{i}=1,2, \ldots, \mathrm{n}$. dan nilai triangular fuzzy didefinisikan $M_{g_{i}}^{j}(\mathrm{j}=1,2, \ldots, \mathrm{m})$ (Özdağoğlu, 2007). Merujuk kepada penelitian Veerabathiran (2012) konsep dasar dan langkah langkah model Fuzzy Synthetic Extent yang digunakan dalam penelitian ini adalah seperti persamaan $4-14$ berikut ::

1. Merumuskan Nilai Fuzzy Synthetic Extent untuk $i$-objek dengan formula berikut :

$$
S_{1}=\sum_{j=1}^{m} M_{g i}^{j} x\left[\sum_{i=1}^{n} \sum_{j=1}^{m} M_{g i}^{j}\right]^{-1}
$$

Untuk $\sum_{j=1}^{m} M_{g i}^{j}$ merupakan operasi penjumlahan nilai extent analysis. $M$ untuk matriks sebagian dengan menggunakan proses operasi penjumlahan pada tiap bilangan triangular fuzzy dalam setiap baris seperti berikut :

$$
\sum_{j=1}^{m} M_{g i}^{j}=\sum_{j=1}^{m} l_{j} \sum_{j=1}^{m} m_{j} \sum_{j=1}^{m} u_{j}
$$

Keterangan :

$\mathrm{M} \quad=$ Triangular Fuzzy Number dengan $g$ parameter $l, m, u$

$\mathrm{j}, \mathrm{i} \quad=$ Kolom, baris

Perhitungan $\left[\sum_{i=1}^{n} \sum_{j=1}^{m} M_{g i}^{j}\right]$ menggunakan operasi penjumlahan untuk keseluruhan bilangan triangular fuzzy $M_{g i}^{j}(j=1,2 \ldots, m)$ maka :

$$
\begin{aligned}
& {\left[\sum_{i=1}^{n} \sum_{j=1}^{m} M_{g i}^{j}\right]=\left[\sum_{i=1}^{m} l_{i} \sum_{i=1}^{m} m_{i} \sum_{i=1}^{m} u_{i}\right]} \\
& {\left[\sum_{i=1}^{n} \sum_{j=1}^{m} M_{g i}^{j}\right]^{-1}=\left[\frac{1}{\sum_{i=1}^{n} u_{i}}, \frac{1}{\sum_{i=1}^{n} m_{i}}, \frac{1}{\sum_{i=1}^{n} l_{i}}\right]}
\end{aligned}
$$

2. Melakukan perbandingan tingkat kemungkinan antara bilangan fuzzy

Untuk mendapatkan perkiraan dari masing masing nilai bobot kriteria maka perlu pertimbangan perbandingan tingkat kemungkinan antara Triangular Fuzzy Number. Sebagai contoh jika terdapat dua bilangan fuzzy $\mathrm{M}_{1}=\left(l_{1}, m_{1}, u_{1}\right)$ dan $\mathrm{M}_{2}=\left(l_{2}, m_{2}, u_{2}\right)$ dengan tingkat kemungkinan $\mathrm{M}_{1} \geq \mathrm{M}_{2}$, dapat didefinisikan sebagai berikut :

$$
V\left(\mathrm{M}_{1} \geq \mathrm{M}_{2}\right)=\sup _{y \geq x}\left[\min \left(\mu_{1}(x),\left(\mu_{1}(y)\right)\right]\right.
$$

Keterangan :

$$
\begin{aligned}
& \quad \sup _{1} \quad=\text { batas teratas himpunan yang paling kecil } \\
& \quad \mathrm{M}_{1}, \mathrm{M}_{2}=(i=1,2, \ldots k) \text { ditentukan dengan operasi max min persamaan } 9 \\
& V\left(\mathrm{M} \geq \mathrm{M}_{1}, \mathrm{M}_{2}, \ldots \mathrm{M}_{k}\right) \\
& =V\left[\left\{\mathrm{M} \geq \mathrm{M}_{1}\right\} \operatorname{dan}\left\{\geq \mathrm{M}_{2}\right\}, \ldots,\left\{\mathrm{M} \geq \mathrm{M}_{k}\right\}\right] \min V\left(\mathrm{M} \geq \mathrm{M}_{1}\right)
\end{aligned}
$$

Jika diasumsikan bahwa :

$$
d^{1}\left(A_{i}\right)=\min V\left(\left(S_{1} \geq S_{k}\right) \text { untuk } k=1,2, \ldots, n ; k \neq i\right.
$$

Maka vektor didefinisikan :

$$
W^{1}=\left(d^{1}\left(A_{1}\right),\left(d^{1}\left(A_{2}\right), \ldots,\left(d^{1}\left(A_{n}\right)^{T}\right.\right.\right.
$$

Dimana $A_{i}=(i=1,2, \ldots, n)$, dan $d^{1}\left(A_{1}\right)$ adalah nilai pilihan relative masing masing atribut keputusan. 
3. Defuzzifikasi

Defuzzifikasi memodifikasi fuzzy output menjadi output yang bernilai tunggal (crisp rule) berdasarkan fungsi keanggotaan yang telah ditentukan. Jika vektor bobot di deffuzifikasi maka akan diperoleh definisi vektor bobot berikut :

$$
\left.W=d\left(A_{1}\right) d^{1}\left(A_{1}\right), \ldots,\left(A_{n}\right)\right)^{T}
$$

Perumusan normalisasinya adalah :

$$
d\left(A_{n}\right)=\frac{d\left(A_{n}\right)}{\sum_{i=1}^{n} d^{\prime}\left(A_{n}\right)}
$$

\section{PENGUMPULAN DATA}

Data yang dibutuhkan dalam penelitian ini terdiri dari data primer dan data sekunder. Data primer merupakan data yang dibutuhkan untuk menganalisis nilai faktor risiko dan membentuk hierarki penilaian keputusan (kriteria/subkriteria) untuk mendapatkan bobot prioritas dan menentukan kategori risiko. Data primer didapatkan dengan melakukan penyebaran kuisioner. Kuisioner dilakukan dua tahap. Kuisioner tahap 1 menentukan skala kemungkinan dan dampak elemen risiko untuk mecari nilai faktor risiko. kuisioner tahap 2 untuk membobotkan elemen-elemen pada model hierarki dengan menggunakan perbandingan berpasangan. Data sekunder didapat dari daftar identifikasi risiko yang diperoleh dari Puslitbang Pd T-01-2005-B sebagai elemen risiko yang selanjutnya disusun sebagai daftar risiko, daftar risiko tersebut ditampilkan pada Tabel 6 berikut. 
Tabel 6. Daftar Identifikasi Risiko

\begin{tabular}{|c|c|c|c|c|c|}
\hline No & Kode Risiko & Identifikasi Risiko & No & Kode Risiko & Identifikasi Risiko \\
\hline $\mathrm{I}$ & TPK & Tahap Pra Konsruksi & II & TK & Tahap Konstruksi \\
\hline 1 & PKPE & Perijinan & 1 & KBIA & Pembiayaan \\
\hline $\mathrm{a}$ & PKPE01 & Proses Tender & $\mathrm{a}$ & KBIA01 & Kontinuitas sumber dana \\
\hline $\mathrm{b}$ & PKPE02 & Dokumen Kontrak & $\mathrm{b}$ & KBIA02 & Bunga masa konstruksi \\
\hline 2 & PKDI & Disain & $\mathrm{c}$ & KBIA03 & Obligasi / bond \\
\hline $\mathrm{a}$ & PKDI01 & Standard & $\mathrm{d}$ & KBIA04 & Pengembalian Pinjaman \\
\hline $\mathrm{b}$ & PKDI02 & Misinterpretasi & 2 & KLAT & Peralatan \\
\hline 3 & PKST & Studi & $\mathrm{a}$ & KLAT01 & Impor \\
\hline $\mathrm{a}$ & PKST02 & Data yang digunakan & $\mathrm{b}$ & KLAT02 & Kinerja \\
\hline $\mathrm{b}$ & PKST01 & Asumsi yang diambil & 3 & KPEM & Pembangunan \\
\hline 4 & PKLA & Pembebasan lahan & $\mathrm{a}$ & KPEM01 & Kondisi Lapangan \\
\hline $\mathrm{a}$ & PKLA01 & Ketersediaan lahan & $\mathrm{b}$ & KPEM02 & Kondisi Cuaca \\
\hline $\mathrm{b}$ & PKLA02 & Proses ganti rugi & c & KPEM03 & Pasokan Material \\
\hline $\mathrm{c}$ & PKLA03 & Penolakan masyarakat & $\mathrm{d}$ & KPEM04 & Pencurian \\
\hline $\mathrm{d}$ & PKLA04 & Banyaknya calo tanah & $\mathrm{e}$ & KPEM05 & Spesifikasi \\
\hline & & & $\mathrm{f}$ & KPEM06 & Mis manajemen \\
\hline & & & $\mathrm{g}$ & KPEM07 & Mogok \\
\hline & & & $\mathrm{h}$ & KPEM08 & Schedule \\
\hline & & & $\mathrm{i}$ & KPEM09 & Estimasi Biaya \\
\hline & & & $\mathrm{j}$ & KPEM10 & Inflasi \\
\hline & & & $\mathrm{k}$ & KPEM11 & Ketidakjujuran \\
\hline & & & 4 & KFOR & Force Majeure \\
\hline & & & $\mathrm{a}$ & KFOR01 & Bencana \\
\hline & & & $\mathrm{b}$ & KFOR02 & Nasionalisasi \\
\hline & & & c & KFOR03 & Revolusi \\
\hline
\end{tabular}

\section{ANALISIS PENELITIAN}

Langkah awal dalam menganalisis bobot risiko dengan FAHP adalah memastikan konsistensi setiap jawaban responden agar hasil yang didapatkan dinilai valid. Analisa konsistensi dapat menggunakan aturan dalam pembahasan pada metode penelitian. berikut dijabarkan aplikasi perhitungan konsistensi pada risiko tahap konstruksi dari responden 1.

Tabel 7. Data Perbandingan Berpasangan

\begin{tabular}{ccccc}
\hline \multicolumn{5}{c}{ Tahap Risiko Kons truksi - Responden 1 (R1) } \\
\hline Kode Risiko & PKPE & PKST & PKDI & PKLA \\
\hline PKPE & 1 & 0.333 & 0.25 & 0.2 \\
PKST & 3 & 1 & 0.25 & 0.333 \\
PKDI & 4 & 2 & 1 & 0.333 \\
PKLA & 5 & 3 & 3 & 1 \\
\hline Total & 13 & 6.333 & 4.5 & 1.833 \\
\hline
\end{tabular}


Selanjutnya analisa nilai CR dari data responden diatas ditampilkan pada Tabel 8 dibawah ini. Dimana sebuah data dinilai konsisten apabila nilai CR $\leq 10 \%$.

Tabel 8. Nilai Consistency Ratio

\begin{tabular}{|c|c|c|c|c|c|c|c|c|}
\hline $\begin{array}{l}\text { Kode } \\
\text { Risiko }\end{array}$ & PKPE & PKST & PKDI & PKLA & V & $\mathrm{W}(\mathrm{v})$ & $\mathrm{N}$ & $\begin{array}{l}\text { Eigen } \\
\text { Value }\end{array}$ \\
\hline PKPE & 0,0769 & 0,0526 & 0,0556 & 0,1071 & 0,0731 & 0,2920 & 0,0721 & 0,9374 \\
\hline PKST & 0,2308 & 0,1579 & 0,0556 & 0,1786 & 0,1557 & 0,6106 & 0,1508 & 0,9549 \\
\hline PKDI & 0,3077 & 0,3158 & 0,2222 & 0,1786 & 0,2561 & 1,0314 & 0,2547 & 1,1461 \\
\hline PKLA & 0,3846 & 0,4737 & 0,6667 & 0,5357 & 0,5152 & 2,1158 & 0,5224 & 0,9752 \\
\hline Total & 1 & 1 & 1 & 1 & 1 & 4,0499 & 1 & 4,0136 \\
\hline \multicolumn{8}{|c|}{ Consistency Index $(\mathrm{CI})$} & 0,0045 \\
\hline \multicolumn{8}{|c|}{ Consistency Ratio (CR) } & 0,005 \\
\hline
\end{tabular}

Setelah data responden dinilai konsisten lanjutkan analisis perhitungan bobot risiko dengan persamaan Fuzzy Synthetic Extent dimana hasil dari analisis dijelaskan pada Tabel 9.

\section{HASIL DAN PEMBAHASAN}

Setelah data responden dianalisis didapatkan bobot risiko dan kategori risiko yang selanjutnya akan dibandingkan dengan bobot risiko atau faktor andil yang dikeluarkan oleh Puslitbang Pd T -01-2005-B. Nilai perbandingan dan hasil penelitian ini ditampilkan pada Tabel 9 berikut. 
Tabel 9. Bobot Prioritas dan Kategori Risiko

\begin{tabular}{|c|c|c|c|c|c|c|c|c|}
\hline \multirow[b]{2}{*}{ No } & \multirow[b]{2}{*}{ Kode Risiko } & \multirow[b]{2}{*}{ Daftar Risiko } & \multicolumn{2}{|c|}{ Bobot Prioritas } & \multicolumn{3}{|c|}{ Risk } & \multirow[b]{2}{*}{ Kategori } \\
\hline & & & \begin{tabular}{|c} 
Puslitbang \\
Pd T -01- \\
$2005-B$ \\
\end{tabular} & Penelitian & $\mathrm{P}(\mathrm{e})$ & I( e ) & $\mathrm{RS}$ & \\
\hline $\mathrm{I}$ & TPK & Tahap Pra Konstruksi & $37,90 \%$ & $56,41 \%$ & 4 & 4 & 16 & Tinggi \\
\hline 1 & PKPE & Perijinan & \multirow{3}{*}{$0,00 \%$} & $3,16 \%$ & 2 & 4 & 8 & Sedang \\
\hline $\mathrm{a}$ & PKPE01 & Proses Tender & & $1,36 \%$ & 2 & 4 & 8 & Sedang \\
\hline $\mathrm{b}$ & PKPE02 & Dokumen Kontrak & & $1,80 \%$ & 3 & 3 & 9 & Sedang \\
\hline 2 & PKDI & Disain & \multirow{3}{*}{$2,50 \%$} & $10,69 \%$ & 3 & 4 & 12 & Tinggi \\
\hline $\mathrm{a}$ & PKDI01 & Standard & & $1,82 \%$ & 3 & 4 & 12 & Tinggi \\
\hline $\mathrm{b}$ & PKDI02 & Misinterpretasi & & $8,87 \%$ & 3 & 5 & 15 & Tinggi \\
\hline 3 & PKST & Studi & \multirow{3}{*}{$1,50 \%$} & $15,47 \%$ & 3 & 4 & 12 & Tinggi \\
\hline $\mathrm{a}$ & PKST02 & Data yang digunakan & & $5,46 \%$ & 3 & 4 & 12 & Tinggi \\
\hline $\mathrm{b}$ & PKST01 & Asumsi yang diambil & & $10,01 \%$ & 3 & 5 & 15 & Tinggi \\
\hline 4 & PKLA & Pembebasan lahan & \multirow{5}{*}{$33,90 \%$} & $27,09 \%$ & 4 & 4 & 16 & Tinggi \\
\hline $\mathrm{a}$ & PKLA01 & Ketersediaan lahan & & $0,38 \%$ & 2 & 3 & 6 & Rendah \\
\hline $\mathrm{b}$ & PKLA02 & Proses ganti rugi & & $7,98 \%$ & 4 & 5 & 20 & Sangat Tinggi \\
\hline $\mathrm{c}$ & PKLA03 & Penolakan masyarakat & & $8,81 \%$ & 3 & 3 & 9 & Sedang \\
\hline $\mathrm{d}$ & PKLA04 & Banyaknya calo tanah & & $9,92 \%$ & 5 & 5 & 25 & Sangat Tinggi \\
\hline II & TK & Tahap Konstruksi & $62,10 \%$ & $43,59 \%$ & 3 & 4 & 12 & Tinggi \\
\hline 1 & KBIA & Pembiayaan & \multirow{5}{*}{$0,00 \%$} & $2,47 \%$ & 3 & 3 & 9 & Sedang \\
\hline $\mathrm{a}$ & KBIA01 & Kontinuitas sumber dana & & $0,05 \%$ & 2 & 3 & 6 & Rendah \\
\hline $\mathrm{b}$ & KBIA02 & Bunga masa konstruksi & & $0,18 \%$ & 1 & 2 & 2 & Sangat Rendah \\
\hline $\mathrm{c}$ & KBIA03 & Obligasi / bond & & $0,49 \%$ & 1 & 2 & 2 & Sangat Rendah \\
\hline $\mathrm{d}$ & KBIA04 & Pengembalian Pinjaman & & $1,76 \%$ & 3 & 3 & 9 & Sedang \\
\hline 2 & KLAT & Peralatan & \multirow{3}{*}{$5,00 \%$} & $8,52 \%$ & 2 & 4 & 8 & Sedang \\
\hline $\mathrm{a}$ & KLAT01 & Impor & & $1,45 \%$ & 1 & 2 & 2 & Sangat Rendah \\
\hline $\mathrm{b}$ & KLAT02 & Kinerja & & $7,07 \%$ & 3 & 4 & 12 & Tinggi \\
\hline 3 & KPEM & Pembangunan & \multirow{12}{*}{$50,10 \%$} & $13,43 \%$ & 3 & 4 & 12 & Tinggi \\
\hline $\mathrm{a}$ & KPEM01 & Kondisi Lapangan & & $1,75 \%$ & 3 & 4 & 12 & Tinggi \\
\hline $\mathrm{b}$ & KPEM02 & Kondisi Cuaca & & $1,57 \%$ & 4 & 4 & 16 & Tinggi \\
\hline $\mathrm{c}$ & KPEM03 & Pasokan Material & & $1,55 \%$ & 3 & 4 & 12 & Tinggi \\
\hline $\mathrm{d}$ & KPEM04 & Pencurian & & $1,54 \%$ & 3 & 5 & 15 & Tinggi \\
\hline $\mathrm{e}$ & KPEM05 & Spesifikasi & & $1,50 \%$ & 3 & 5 & 15 & Tinggi \\
\hline $\mathrm{f}$ & KPEM06 & Mismanajemen & & $1,42 \%$ & 4 & 4 & 16 & Tinggi \\
\hline $\mathrm{g}$ & KPEM07 & Mogok & & $1,22 \%$ & 3 & 3 & 9 & Sedang \\
\hline $\mathrm{h}$ & KPEM08 & Schedule & & $1,16 \%$ & 2 & 4 & 8 & Sedang \\
\hline $\mathrm{i}$ & KPEM09 & Estimasi Biaya & & $0,96 \%$ & 2 & 3 & 6 & Rendah \\
\hline $\mathrm{j}$ & KPEM10 & Inflasi & & $0,68 \%$ & 2 & 3 & 6 & Rendah \\
\hline $\mathrm{k}$ & KPEM11 & Ketidakjujuran & & $0,07 \%$ & 3 & 4 & 12 & Tinggi \\
\hline 4 & KFOR & Force Majeure & \multirow{4}{*}{$7,00 \%$} & $19,16 \%$ & 3 & 3 & 9 & Sedang \\
\hline $\mathrm{a}$ & KFOR01 & Bencana & & $2,11 \%$ & 2 & 1 & 2 & Sangat Rendah \\
\hline $\mathrm{b}$ & KFOR02 & Nasionalisasi & & $2,67 \%$ & 3 & 2 & 6 & Rendah \\
\hline $\mathrm{c}$ & KFOR03 & Revolusi & & $14,38 \%$ & 3 & 5 & 15 & Tinggi \\
\hline
\end{tabular}


Bobot prioritas merupakan nilai berupa persentase yang dapat dijadikan sebagai tolak ukur untuk menghitung seberapa besar pengaruh bobot tersebut terhadap prioritas sebuah elemen yang disebut dengan faktor andil. Bobot prioritas tersebut dapat digunakan sebagai salah satu dasar untuk penerimaan atau pengalokasian risiko, pengalokasian risiko sebaiknya dilakukan kepada pihak yang dinilai atau dianggap paling mampu untuk mengelola risiko tersebut sehingga risiko tersebut dapat dikendalikan secara optimal.

Berdasarkan Puslitbang Pd T-01-2005-B terdapat besaran faktor andil yang merupakan default model untuk menghitung besaran biaya investasi per komponen biaya. Besaran ini akan dibandingkan dengan bobot prioritas yang telah didapat pada penelitian ini. Berdasarkan Tabel 9 diatas terdapat perbedaaan perbandingan bobot prioritas yang besar antar risiko. Pada Puslitbang Pd T-01-2005-B, risiko tahap pra konstruksi dinilai sebesar 37,90\% sedangkan berdasarkan hasil penelitian bobot prioritas untuk risiko tahap pra konstruksi pada proyek Jalan Tol Padang-Sicincin dinilai sebesar 56,41\% dengan selisih sebesar 18,51\% artinya elemenelemen risiko pada risiko tahap konstruksi memiliki pengaruh risiko sebesar 56,41\% terhadap risiko investasi proyek Jalan Tol Padang-Sicincin

Untuk tahap konstruksi bobot prioritas pada puslitbang dinilai sebesar $62,10 \%$ sedangkan berdasarkan hasil penelitian bobot prioritas untuk risiko tahap konstruksi pada proyek jalan tol padang-sicincin dinilai sebesar 43,59\% dengan selesih sebesar 18,51\% artinya elemen-elemen risiko pada risiko tahap konstruksi memiliki pengaruh risiko sebesar 43,59\% terhadap risiko investasi proyek Jalan Tol Padang-Sicincin.

\section{KESIMPULAN DAN SARAN}

Penelitian ini bertujuan untuk menganalisis bobot guna mendapatkan prioritas dari risiko investasi pada tahap pra konsruksi dan tahap konsruksi serta membandingkan nilai tersebut dengan besaran factor andil dari Puslitbang Pd T -01-2005-B dan menganalisis nilai risiko investasi untuk kategori risiko. Sesuai dengan tujuan penelitian ini dapat ditarik kesimpulan bahwa nilai bobot prioritas untuk tahap pra konstruksi dan tahap konstruksi pada Proyek Jalan Tol Padang-Sicincin adalah 56,41\% dan 43,59\%. Risiko tahap pra konstruksi dan risiko konstruksi dikategorikan sebagai risiko tinggi dengan nilai skala risiko masing-masing adalah 16 dan 12. Risiko yang memiliki kategori risiko sangat tinggi terdapat pada risiko ketersediaan lahan (PKLA01) dan risiko penolakan masyarakat (PKLA03) Risiko dengan nilai bobot prioritas paling tinggi terdapat pada risiko pembebasan lahan untuk tahap pra konstruksi dan risiko force majeur pada tahap konstruksi.

Berdasarkan penelitian yang telah dilakukan terdapat beberapa saran untuk investor, pemerintah dan untuk penelitian selanjutnya yang dijabarkan sebagaia berikut :

1. Investor: Segala sesuatu risiko yang mungkin terjadi harus bisa diprediksi terkait potensi kerugian yang mungkin dialami saat ketika berinvestasi. Setelah mengetahui risiko yang mungkin terjadi, selanjutnya bisa mengambil rencana atau tindakan untuk mengurangi risiko tersebut sesuai dengan tujuan investasi.

2. Pemerintah: Dalam proses pembebasan lahan sebaiknya pemerintah ikut ambil andil dalam proses pengamanan terkait dengan isu revolusi dimasing-masing daerah untuk memperlancar proses pembangunan infrastruktur di Indonesia.

3. Penelitian selanjutnya : Agar peneliti selanjutnya yang menggunakan variabel linguistik dengan metode FAHP memperhatikan konsistensi responden pada saat pengambilan data.

\section{DAFTAR PUSTAKA}

Abbasianjahromi, H., Rajaie, H., \& Shakeri, E. (2013). "A Framework for Subcontractor Selection In The Construction Industry". Journal of Civil Engineering and Management, 19(2), 158-168. https://doi.org/10.3846/13923730.2012.743922

Ahmed, F., \& Kilic, K. (2016). "Comparison of Fuzzy Extent Analysis Technique and Its 
Extensions with Original Eigen Vector Approach". ICEIS 2016 - Proceedings of the 18th International Conference on Enterprise Information Systems, 2(1), 174-179. https://doi.org/10.5220/0005868401740179

Baccarini, D., \& Archer, R. (2001). "The Risk Ranking of Projects: A Methodology". International Journal of Project Management, 19(3), 139-145. https://doi.org/10.1016/S0263-7863(99)00074-5

Boender, C., De Graan, J., and Lootsma, F. (1989). "Multi- Criteria Decision Analysis with Fuzzy Pairwise Comparisons". Fuzzy Sets and System, 29(2), 133-143. https://doi.org/10.1016/0165-0114(89)90817-5

Buckley, J. J. (1985). "Fuzzy Hierarchical Analysis". Fuzzy Sets and System, 17(3), 233-247. https://doi.org/10.1016/0165-0114(85)90090-9

Chang. (1996). "Applications of The Extent Analysis Method on Fuzzy AHP”. European Journal of Operational Research, 95(3), 649-655. https://doi.org/10.1016/03772217(95)00300-2-5

Deng, H. (1999). "Multicriteria Analysis with Fuzzy Pairwise Comparison." International Journal of Approximate Reasoning 21, 21, 215-231.

Fang, C. (2011). "Modeling and Analysing Propagation Behavior in Complex Risk Network: A Decision Support System for Project Risk Management." ACM Journal, 52(Decision Support System). Retrieved from https://doi.org/10.1016/j.dss.2011.10.021

Marantika, D., Erwinsyah, M. B., Hatmoko, J. U. D., \& Khasani, R. R. (2017). "Analisis Risiko Investasi Proyek Kereta Cepat Jakarta-Bandung". Jurnal Karya Teknik Sipil, 6(1), 324335.

Özdağoğlu, A. (2007). "Comparison of AHP and Fuzzy AHP for the Multi-Criteria Decision Making Processes with Linguistic Evaluations". Istanbul Ticaret Üniversitesi Fen Bilimleri Dergisi, 6(11), 65-85-85.

Pd T-01-2005-B. Pd T-01-2005-B - Pedoman Analisis Risiko Investasi Jalan Tol. Puslitbang Jalan dan Jembatan. Badan Penelitian dan Pengembangan. Kementerian PUPR

Saaty, T. L. (2004). "Fundamentals of The Analytic Network Process - Dependence And Feedback In Decision-Making With A Single Network". Journal of Systems Science and Systems Engineering, 13(2), 129-157.

Suprayitno, H., \& Soemitro, R. A. A. (2018). "Preliminary Reflexion on Basic Principle of Infrastructure Asset Management". Jurnal Manajemen Aset Infrastruktur \& Fasilitas 2(1), 1-10.

Susilo, L. J., \& Kaho, V. R. (2018). Manajemen Risiko Berbasis ISO 31000:2018 ; Panduan untuk Risk Leaders dan Risk Practitioners. Gramedia. Jakarta.

Triantaphyllou, E., \& Mann, S. H. (1995). "Using The Analytic Hierarchy Process For Decision Making In Engineering Applications: Some Challenges". International Journal of Industrial Engineering, 2(1), 35-44.

Van Laarhoven, P. and Pedrycz, W. (1983). “A Fuzzy Extension of Saaty's Priority Theory”. Fuzzy Sets and Systems, 11(1), 199-227. https://doi.org/10.1016/S0165-0114(83)800827

Veerabathiran, R. (2012). "Application of the Extent Analysis Method on Fuzzy AHP". International Journal of Engineering Science and Technology (IJEST), 4(07), 34723480 . 